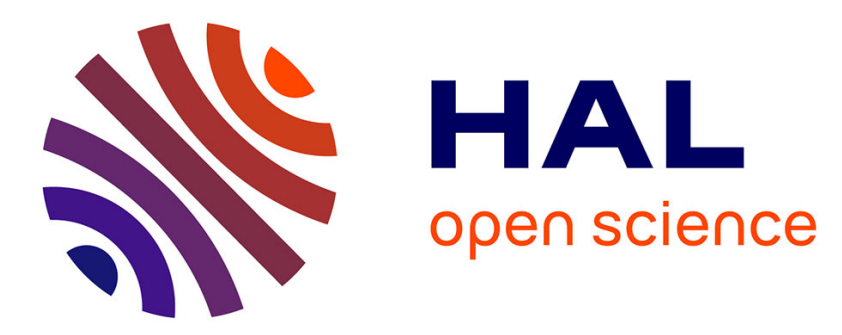

\title{
Organometallic Approach for the Preparation of Zinc Oxide Nanostructured Gas Sensitive Layers
}

Justyna Jońca, Myrtil L. Kahn, Katia Fajerwerg, Bruno Chaudret, Audrey Chapelle, Philippe Menini, Pierre Fau

\section{- To cite this version:}

Justyna Jońca, Myrtil L. Kahn, Katia Fajerwerg, Bruno Chaudret, Audrey Chapelle, et al.. Organometallic Approach for the Preparation of Zinc Oxide Nanostructured Gas Sensitive Layers. Key Engineering Materials, 2015, 644, pp.22-25. 10.4028/www.scientific.net/KEM.644.22 . hal-02045551

\section{HAL Id: hal-02045551 \\ https://hal.science/hal-02045551}

Submitted on 6 Jun 2019

HAL is a multi-disciplinary open access archive for the deposit and dissemination of scientific research documents, whether they are published or not. The documents may come from teaching and research institutions in France or abroad, or from public or private research centers.
L'archive ouverte pluridisciplinaire $\mathbf{H A L}$, est destinée au dépôt et à la diffusion de documents scientifiques de niveau recherche, publiés ou non, émanant des établissements d'enseignement et de recherche français ou étrangers, des laboratoires publics ou privés. 


\title{
Organometallic approach for the preparation of zinc oxide nanostructured gas sensitive layers
} JOŃCA Justyna ${ }^{1, a}$, KAHN L. Myrtil ${ }^{1, b}$, FAJERWERG Katia ${ }^{1,2, c}$, CHAUDRET
Bruno $^{3, d}$, CHAPELLE Audrey

\author{
${ }^{1}$ Laboratoire de Chimie de Coordination (LCC), CNRS, 205 route de Narbonne, 31077 Toulouse \\ Cedex 4, France \\ ${ }^{2}$ Université Paul Sabatier, UT III, 118 route de Narbonne, 31062 Toulouse Cedex 9, France \\ ${ }^{3}$ Laboratoire de Physique et de Chimie des Nano-objets (LPCNO), INSA, UPS, CNRS, 135 avenue \\ de Rangueil, 31077 Toulouse, Cedex 4, France \\ ${ }^{4}$ Laboratoire d'Analyse et d'Architecture des Systèmes (LAAS), CNRS, 7 avenue du Colonel \\ Roche, 31400 Toulouse

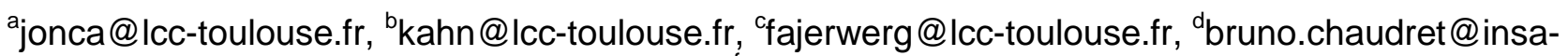

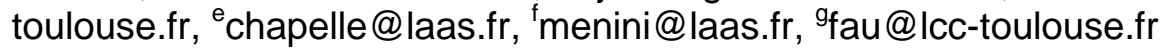

Keywords: gas sensor, $\mathrm{ZnO}$, organometallic synthesis

\begin{abstract}
A reproducible organometallic approach was used in order to prepare zinc oxide gas sensitive layers. Various $\mathrm{ZnO}$ nanostructures with well-defined morphology were prepared by controlled hydrolysis of suitable organometallic precursor. These nanomaterials were deposited on miniaturized gas sensors substrates by an ink-jet method. The as prepared devices were tested towards different reducing gases, namely: $\mathrm{CO}, \mathrm{C}_{3} \mathrm{H}_{8}$, and $\mathrm{NH}_{3}$. We showed that the morphology of these nanostructures significantly influences the sensor response level to the reducing gases.
\end{abstract}

\section{Introduction}

The achievement of highly sensitive sensors can be accomplished by using materials with very small grains thanks to thier high surface-to-volume ratio [1, 2]. Therefore, the controlled synthesis of nano- or microsized particles with different morphology has attracted considerable interest [3]. It is well known that the successful control of these parameters depends strongly on the synthetic method used for the nanostructures preparation. Compared with high temperature vapor phase method, solution based synthesis methods can be conducted at low temperatures and offer additional advantages such as straightforward processing, low cost, and eases of scale up [4]. Among them, the organometallic approach presents several advantages to get well-controlled nanostructures in terms of size dispersion, chemical composition, surface properties, shape or organization. Few metal oxides $\left(\mathrm{ZnO}, \mathrm{SnO}_{2}, \mathrm{In}_{2} \mathrm{O}_{3}\right.$, and $\left.\mathrm{RuO}_{2}\right)$ were obtained in our laboratory by oxidation of metal NPs prepared from organometallic precursors [5, 6]. Moreover, the extension of this method, based on the controlled hydrolysis of metal precursors in the presence of alkylamines ligands, allowed a direct access to well defined nanostructures of magnetic metal oxides (NiO, $\gamma$ $\mathrm{Fe}_{2} \mathrm{O}_{3}, \mathrm{FeO}$ ) [7-9] and semi-conducting oxides ( $\left.\mathrm{ZnO}\right)$ [10-12] by a one-step procedure. Drawing from this research, $\mathrm{ZnO}$ nanostructures were synthetized and used as gas sensitive layers. The results suggest that the morphology of zinc oxide nanostructures can influence the sensor performance.

\section{Materials and Methods}

Organometallic precursor $\left(\mathrm{Zn}\left(\mathrm{c}-\mathrm{C}_{6} \mathrm{H}_{11}\right)_{2}\right.$, NanoMePS) and octylamine (Sigma Aldrich) were stored in the glovebox. THF was collected after going through drying columns (MB-SPS-800 solvent purification system) prior to use. Distilled water was degassed with argon during $30 \mathrm{~min}$ prior to use. All reactions were performed at room temperature and under argon atmosphere in standard Schlenk tubes except for $\mathrm{ZnO}$ nanorods which were prepared in a flat-bottomed reactor. 
$\mathrm{ZnO}$ cloudy-like nanoparticles were obtained from a THF (4 mL) solution of $\mathrm{Zn}\left(\mathrm{c}-\mathrm{C}_{6} \mathrm{H}_{11}\right)_{2}$ $(0.25 \mathrm{mmol}, 57.9 \mathrm{mg})$. The hydrolysis was performed by addition of THF $(2 \mathrm{~mL})$ containing water $(1 \mathrm{mmol}, 18 \mu \mathrm{L})$ to this solution. After $16 \mathrm{~h}$, the nanoparticles and solvent were separated by centrifugation $\left(5 \mathrm{~min}, 5000 \mathrm{rpm}, 20^{\circ} \mathrm{C}\right.$, here and after).

$\mathrm{ZnO}$ isotropic nanoparticles were obtained from a THF $(4 \mathrm{~mL})$ solution of $\mathrm{Zn}\left(\mathrm{c}-\mathrm{C}_{6} \mathrm{H}_{11}\right)_{2}$ $(0.25 \mathrm{mmol}, 57.9 \mathrm{mg})$. Octylamine $(0.25 \mathrm{mmol}, 32.5 \mathrm{mg})$ was used as growth orienting ligand. The hydrolysis was performed by addition of THF $(2 \mathrm{~mL})$ containing water $(1 \mathrm{mmol}, 18 \mu \mathrm{L})$ to this solution. After $16 \mathrm{~h}$ the nanoparticles and solvent were separated by centrifugation and the nanoparticles were washed 3 times with $5 \mathrm{~mL}$ of acetone (Sigma Aldrich).

$\mathrm{ZnO}$ nanorods were obtained from a mixture of $\mathrm{Zn}\left(\mathrm{c}-\mathrm{C}_{6} \mathrm{H}_{11}\right)_{2}(0.25 \mathrm{mmol}, 57.9 \mathrm{mg})$ and octylamine $(0.5 \mathrm{mmol}, 65 \mathrm{mg})$. The hydrolysis was performed by addition of water to the reactor (1 mmol, $18 \mu \mathrm{L}$ ). The reaction system was left for 4 days. Then the nanorods were dispersed in THF $(6 \mathrm{~mL})$. Afterwards, the nanorods and the solvent were separated by centrifugation. Finally, the nanorods were washed 3 times with $5 \mathrm{~mL}$ of acetone.

TEM specimens were prepared on carbon-supported copper grids. TEM images were obtained using a Hitachi 7700 microscope operating at $80 \mathrm{kV}$.

Sensors preparation: All freshly prepared and washed nanostructures were dispersed in ethanol (Sigma Aldrich). The concentration of the nanostructures in the solution was $5 \mathrm{mg} \mathrm{mL} \mathrm{mL}^{-1}$. The solutions were then deposited on miniaturized gas sensors substrates [13] by an ink-jet method (Microdrop AG) [14] (Fig. 1).
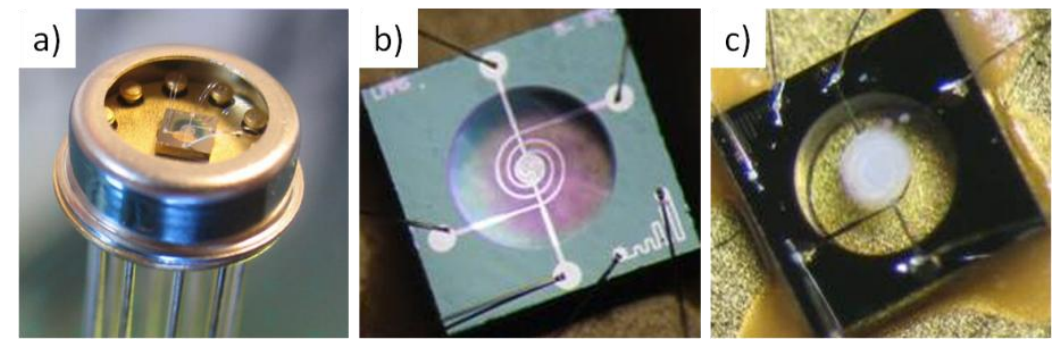

Fig. 1. Gas sensor substrate (a), silicon platform before (b) and after (c) sensitive layer deposition.

Gas tests were performed using a PC controlled setup composed of different gas bottles connected to adequate mass flow controllers (QualiFlow) commanded by Data Acquisition/Switch Unit 34970A. Sensors were placed in a specially designed measurement cell containing also the humidity and temperature sensors commanded by another Data Acquisition/Switch Unit 34970A. The heater was commanded by HP6642A tension controller. The NI 6035E electronic card established the connection between computer and measurements. Freshly prepared sensors were conditioned by successive in situ heating of the sensitive layers up to $500^{\circ} \mathrm{C}$ in synthetic air and at humidity up to $50 \%$. The total gas flow rate was $1 \mathrm{~L} / \mathrm{min}$. All tests were also performed at these conditions. Firstly, sensors were stabilized in synthetic air for $2 \mathrm{~h}$. Then, all sensors were exposed for 15 min to reducing gas mixture containing synthetic air and one of reducing gases, namely: CO, $\mathrm{C}_{3} \mathrm{H}_{8}$, or $\mathrm{NH}_{3}$. Resistance was measured before and after sensors exposure to reducing gas mixture and the sensitivity (\%) to each gas was calculated as $S=\left(R_{\text {air }}-R_{\text {gas }}\right) / R_{\text {air }}{ }^{*} 100$, where $R_{\text {air }}-$ sensor resistance in synthetic air, $\mathrm{R}_{\mathrm{gas}}-$ sensor resistance in reducing gas mixture.

\section{Results and discussion}

TEM images of the nanostructures (Fig. 2) showed that under various reaction conditions it is possible to master the morphology of the $\mathrm{ZnO}$ particles prepared by the organometallic approach. The hydrolysis of zinc precursor, [ $\mathrm{Zn}\left(\mathrm{c}-\mathrm{C}_{6} \mathrm{H}_{11}\right)_{2}$ ], led to the formation of either cloudy-like nanoparticles, isotropic nanoparticles (diameter of $c a .5 \pm 1 \mathrm{~nm}$ ), or nanorods (diameter of $c a .5 \pm$ $0.8 \mathrm{~nm}$ and length of $c a .20 \mathrm{~nm} \pm 6$ ) made of $\mathrm{ZnO}$. The synthesis and mechanism of the $\mathrm{ZnO}$ particles growth and stabilization have been previously described [12, 15]. The alkylamine ligands play a fundamental role all along the synthesis process and remain coordinated to the particles 
preventing them from aggregation. That is why, the synthesis in the absence of alkylamine led to the formation of agglomerated structures - cloud-like nanoparticles (Fig 2a). The presence of organic solvent (THF) plays also an important role in the nanoparticles growth process (Fig. 2b). Indeed, isotropic nanoparticles are obtained when the synthesis is performed in THF in the presence of alkylamine ligands while the formation of $\mathrm{ZnO}$ nanorods is directly obtained when the synthesis is performed in pure alkylamine. In these conditions, the nanocrystals grow along the $c$ crystallographic axis of the hexagonal $\mathrm{ZnO}$ structure (Fig. 2c).

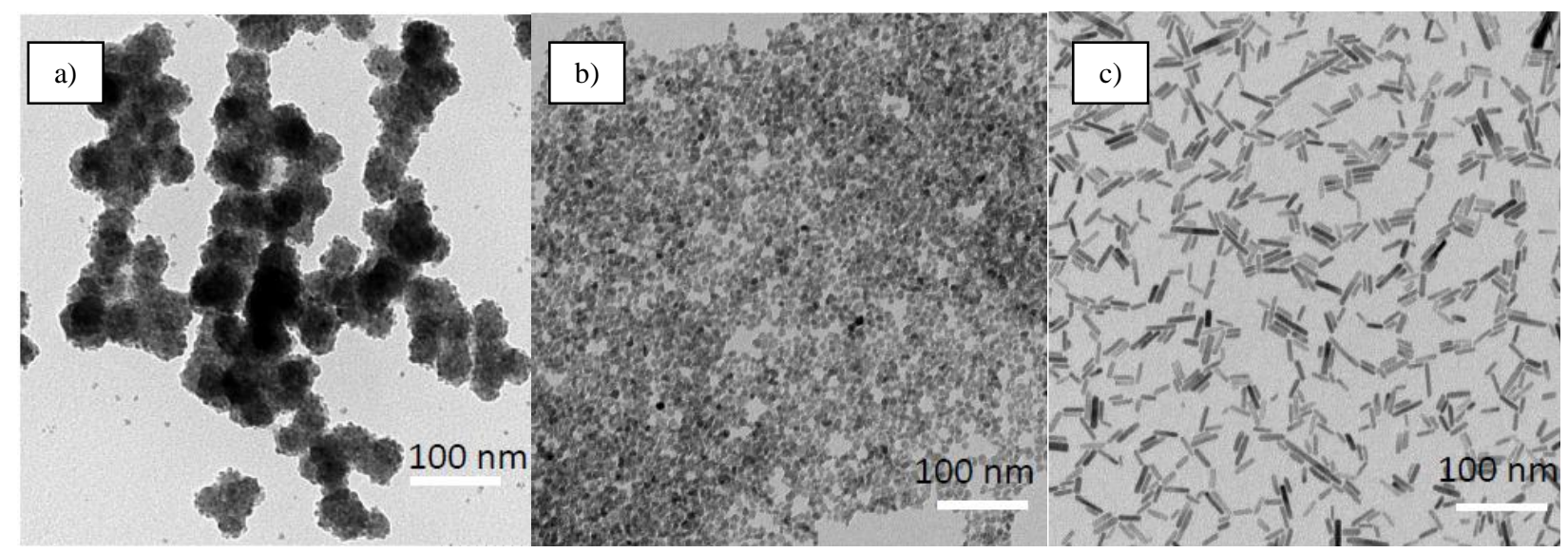

Figure 2. TEM images of various $\mathrm{ZnO}$ nanostructures: cloud-like nanoparticles (a), isotropic nanoparticles (b) and nanorods (c).

After the removal of ligands, all prepared $\mathrm{ZnO}$ nanostructures were ink-jet deposited on a miniaturized gas sensors substrates to be used as gas sensitive layers. Sensors were exposed to different reducing gases in humid air conditions ( $\mathrm{RH} \mathrm{50 \% )}$ at $500^{\circ} \mathrm{C}$, namely: $100 \mathrm{ppm}$ of $\mathrm{CO}, 100$ ppm of $\mathrm{C}_{3} \mathrm{H}_{8}$, and $5 \mathrm{ppm}$ of $\mathrm{NH}_{3}$. The sensors response towards propane is presented on Fig. 3 and the sensitivities for all the gases are presented in Table 1. In air, the sensitive layers exhibit a resistance of few MOhm. In the presence of reducing gases, the resistance decreased significantly which is characteristic for sensors based on $n$ type semiconductors.
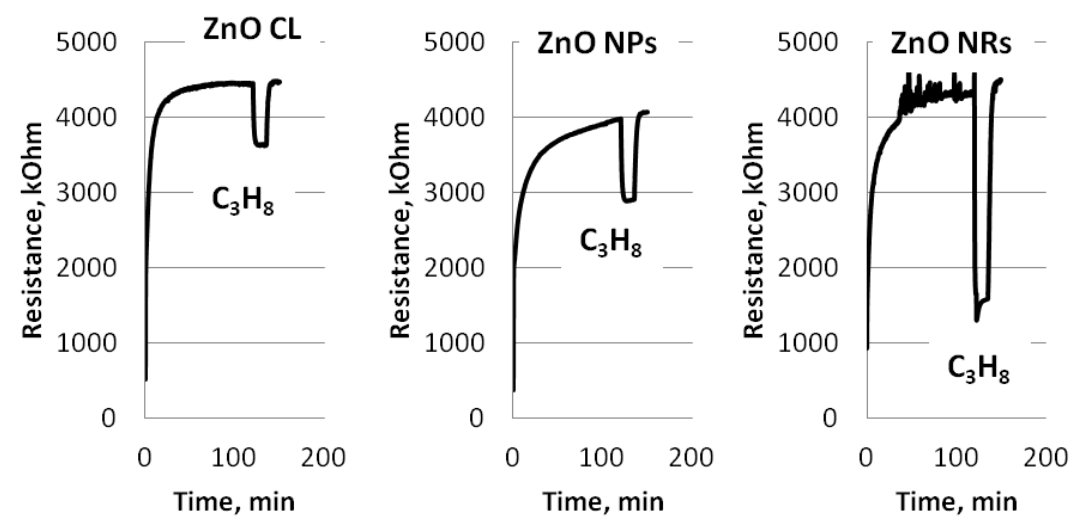

Fig. 3. Example of sensor responses towards propane ( $\mathrm{ZnO} \mathrm{CL} \mathrm{-} \mathrm{cloud-like} \mathrm{nanoparticles,} \mathrm{ZnO} \mathrm{NPs}$ - isotropic nanoparticles, $\mathrm{ZnO} \mathrm{NRs}$ - nanorods).

The highest sensitivity towards $\mathrm{CO}$ and $\mathrm{C}_{3} \mathrm{H}_{8}$ was obtained for $\mathrm{ZnO}$ nanorods with $\mathrm{S}=70 \%$ and $63 \%$, respectively. Cloud-like nanoparticles and isotropic nanoparticles exhibit quite similar sensitivity when exposed to $\mathrm{CO}(\mathrm{ca} .40 \%)$, but $\mathrm{ZnO}$ cloud-like sensors showed the weakest sensitivity towards propane $(\mathrm{S}=10 \%)$. Regardless of the $\mathrm{ZnO}$ sensors, a quite similar sensitivity to $\mathrm{NH}_{3}$ (ca. $\mathrm{S}=5-8 \%$ ) is obtained. These gas-sensing performances highlight the leading role of the nanoparticle's shape on the $\mathrm{CO}$ and especially $\mathrm{C}_{3} \mathrm{H}_{8}$ detections, whereas it is of little importance for 
$\mathrm{NH}_{3}$. These results demonstrate that sensitivity and selectivity can be improved using the same material but modifying only its shape paving the way for new powerful arrays of selective gas sensors.

Table 1. Sensitivity (\%) of $\mathrm{ZnO}$ based sensors toward different reducing gases ( $\mathrm{ZnO} \mathrm{CL}-$ cloudlike nanoparticles, ZnO NPs - isotropic nanoparticles, ZnO NRs - nanorods) with $\mathrm{RH}=50 \%$.

\begin{tabular}{llll} 
& $\mathrm{ZnO} \mathrm{CL}$ & $\mathrm{ZnO}$ NPs & ZnO NRs \\
\hline $100 \mathrm{ppm} \mathrm{CO}_{100 \mathrm{ppm} \mathrm{C}_{3} \mathrm{H}_{8}}^{42}$ & 10 & 39 & 63 \\
$5 \mathrm{ppm} \mathrm{NH} \mathrm{NH}_{3}$ & 8 & 29 & 70 \\
\hline
\end{tabular}

\section{Summary}

Sensors based on different $\mathrm{ZnO}$ nanostructures, prepared following a one-pot organometallic method, were exposed to different reducing gases. The results highlight the influence of the nanostructure's morphology on both the gas sensor sensitivity and selectivity.

\section{References}

[1] F. Lu, Y. Liu, M. Dong, X. P. Wang: Sens. Actuat. B Vol 66 (2000) p. 225

[2] S. G. Ansari, P. Boroojerdian, S. R. Sainkar, R. C. Aiyer, S. K. Kulkarni: Thin Solid Films, Vol. 295 (1997), p. 271

[3] M. K. Franke, T. J. Koplin, U. Simon: Small, Vol. 2, No. 1 (2006), p. 36

[4] B. Weintraub, Z. Zhou, Y. Deng: Nanoscale, Vol. 2 (2010), p. 1573

[5] C. Nayral, E. Viala, P. Fau, F. Senocq, J.-C. Jumas, A. Maisonnat, B. Chaudret : Chem. Eur. J., Vol. 6 (2000), p. 4082

[6] Y. Guari, K. Soulantica, K. Philippot, C. Thieuleux, A. Mehdi, C. Reyé, B. Chaudret and R. J. P. Corriu: New J. Chem., Vol 27 (2003), p. 1029

[7] N. Cordente, B. Toustou, V. Collière, C. Amiens, B. Chaudret, M. Verelst, M. Respaud and J.M. Broto: C. R. Acad. Sci., Ser. IIc: Chim., Vol. 4 (2001), p. 143

[8] A. Glaria, M. L. Kahn, A. Falqui, P. Lecante, V. Collière, M. Respaud and B. Chaudret: ChemPhysChem, Vol. 9, No.14 (2008), p. 2035

[9] A. Glaria, M. L. Kahn, P. Lecante, B. Barbara, B. Chaudret : ChemPhysChem, 2008, 9, p. 776

[10] M. Monge, M. L. Kahn, A. Maisonnat, B. Chaudret: Angew. Chem., Int. Ed., Vol. 42 (2003), p. 5321

[11] M. L. Kahn, A. Glaria, C. Pages, M. Monge, L. Saint Macary, A. Maisonnat, B. Chaudret: J. Mater. Chem., Vol. 19 (2009) 4044

[12] Y. Coppel, G. Spataro, C. Pages, B. Chaudret, A. Maisonnat, M. L. Kahn: Chem. Eur. J., Vol. 18 (2012), p. 5384.

[13] Ph. Menini, H. Chalabi, N. P. Yaboue, E. Scheid, V. Conedera, L. Salvagnac, K. Aguir: Eurosensors XXII proceedings, 2008, 342

[14] Microdrop Technologies:

http://www.microdrop.de/wDeutsch/technology/microdrop.shtml?navid=28

[15] M. L. Kahn, M. Mange, V. Collière, F. Senocq, A. Maisonnat, B. Chaudret: Adv. Funct. Mater. Vol. 15, No. 3 (2005), p. 458 